\title{
ANALISIS MELODI LAGU ANEUK YATIM CIPTAAN RAFLY KANDE
}

\author{
Abdul Rozak ${ }^{1)}$, Haria Nanda Pratama ${ }^{2)}$, Rico Gusmanto ${ }^{3)}$ \\ 1),3) Program Studi Seni Karawitan, Institut Seni Budaya Indonesia Aceh \\ ${ }^{2)}$ Program Studi Seni Teater, Institut Seni Budaya Indonesia Aceh \\ Email:abdulrozak@isbiaceh.ac.id ${ }^{1)}$, harianandapratama@isbiaceh.ac.id ${ }^{2)},{\text { ricogusmanto@isbiaceh.ac.id }{ }^{3)}}^{3}$
}

\begin{abstract}
Aneuk Yatim is a song created in 1999 by Rafly, has a message and meaning of peace in responding to issues of political upheaval in Aceh, and represents the condition of children in Aceh during the conflict. Through lyrics and melody, Rafly is able to create an atmosphere of sadness that can be felt by the community regarding the conditions and situations during the conflict. The vocals in the song Aneuk Yatim, written by Rafly, have a melodic structure and form consisting of musical ornaments, melodic travel arrangements and scales. This study describes the melody in the song Aneuk Yatim written by Rafly Kande using Western music theory. The purpose of this study is to determine the melody analysis method of pop music in Indonesia in general and regional pop music in particular. The approach taken is a qualitative approach, with descriptive analysis methods, assisted by ethical and emic approaches to facilitate the smoothness of the data search process. The selection of methods and approaches is carried out through documentation, observation, and interviews with participants. The form and structure of the melody in the song Aneuk Yatim, written by Rafly Kande, consists of two parts with a tempo of $60 \mathrm{bpm}$, each of which is divided into two sentences / periods. The sentences are arranged based on various forms of motifs, each of which has a melody and scale that is repeated in the next period / sentence with a slight change in the melody at the end of the figures (closing phrase). The scale used in this song is the Original Minor and Harmonious Minor, with sequences development techniques, diminished, and augmented. The results of this study are expected to become a reference and reference in the perspective of formal objects and material objects, related to the analysis of the form and structure of the melody, the development of melodic patterns discussed in Western music theory.
\end{abstract}

Keywords : Aneuk Yatim's Song, Melody Analysis, Western Music Theory

\begin{abstract}
ABSTRAK
Aneuk Yatim adalah lagu yang diciptakan pada tahun 1999 oleh Rafly, memiliki pesan dan makna perdamaian dalam merespon persoalan gejolak politik di Aceh, serta merepresentasikan kondisi anak-anak di Aceh pada masa konflik. Melalui lirik maupun melodi, Rafly mampu menciptakan suasana kesedihan yang dapat dirasakan oleh masyarakat terhadap kondisi dan situasi di masa konflik. Vokal pada lagu Aneuk Yatim ciptaan Rafly memiliki struktur dan bentuk melodi yang terdiri dari ornamen musik, susunan perjalanan melodi dan scale. Penelitian ini menguraikan melodi pada lagu Aneuk Yatim ciptaan Rafly Kande menggunakan teori musik Barat. Tujuan penelitian ini yaitu mengetahui metode analisis melodi pada musik Pop di Indonesia umumnya dan musik Pop daerah khususnya. Pendekatan yang dilakukan adalah pendekatan kualitatif, dengan metode analisis deskriptif, dibantu dengan pendekatan etik dan emik untuk mempermudah kelancaran dalam proses pencarian data. Pemilihan metode dan pendekatan dilakukan melalui dokumentasi, observasi, dan wawancara dengan partisipan. Bentuk dan struktur melodi pada lagu Aneuk Yatim ciptaan Rafly Kande terdiri dari dua bagian dengan tempo 60 bpm, yang masing-masing bagian dibagi dalam dua kalimat/periode. Pada kalimat tersebut disusun berdasarkan bermacam-macam bentuk motif, yang masing-masing motif memiliki melodi dan scale yang diulang pada periode/kalimat selanjutnya dengan sedikit perubahan melodi pada akhir figures (frase penutup). Penggunaan tangganada pada lagu ini adalah Tangganada Minor Asli dan Minor Harmonis, dengan teknik pengembangan sekuen, diminished, dan augmented. Hasil dari penelitian ini diharapkan menjadi acuan dan referensi dalam perspektif objek formal maupun objek material, terkait dengan analisis bentuk dan struktur melodi, pengembangan pola melodi yang dibahas dalam keilmuan musik Barat.
\end{abstract}

Kata Kunci : Lagu Aneuk Yatim, Analisis Melodi, Teori Musik Barat 


\section{Pendahuluan}

Musik konvensional memiliki berbagai macam genre, salah satunya adalah genre musik Pop yang berbentuk lagu atau nyanyian. Perkembangan musik Pop di Indonesia sangat pesat dan digemari oleh hampir semua kalangan masyarakat. Banyak daerah di Indonesia termasuk Aceh telah mengadaptasi musik Pop ke dalam lagu yang menggunakan bahasa lokal. Para musisi Aceh seperti Rafly yang tergabung dalam grup musik Kande, menciptakan karya-karya lagu Pop yang menggunakan bahasa daerah. Salah satu lagu ciptaan Rafly yang dikenal oleh masyarakat luas hingga di luar Aceh adalah Aneuk Yatim.

Aneuk Yatim adalah lagu yang diciptakan pada tahun 1999 oleh Rafly. Lagu ini memiliki pesan dan makna perdamaian dalam merespon persoalan gejolak politik di Aceh. Lagu Aneuk Yatim merepresentasikan kondisi anak-anak di Aceh pada masa konflik. Melalui lirik maupun melodi, Rafly mampu menciptakan suasana kesedihan yang dapat dirasakan oleh masyarakat terhadap kondisi dan situasi di masa konflik dengan waktu yang cukup lama. Tidak hanya masyarakat Aceh, masyarakat di luar Aceh pun akan merasakan kesan kesedihan ketika mendengarkan setiap melodi vokal dari lagu ini. Lagu ini mencapai puncak kepopulerannya saat pasca tsunami melanda Aceh pada tahun 2004. Dengan kata lain, lagu ini menjadi simbol untuk merepresentasikan peristiwa-peristiwa konfilk dan bencana di Aceh. Lagu Aneuk Yatim memiliki unsur-unsur pada melodi vokal dalam menciptakan kesan terhadap peristiwa yang dialami masyarakat Aceh dengan ciri yang khas yang terdapat pada vokal Aceh.

Vokal pada lagu Aneuk Yatim ciptaan Rafly memiliki struktur dan bentuk melodi yang terdiri dari ornamen-ornamen musik serta susunan perjalanan melodi. Ornamen-ornamen musik yang terdapat pada lagu ini diantaranya acciacatura dan appogiatura, sedangkan perjalanan melodi atau interval nada menggunakan scale tersendiri. Dengan demikian, unsur-unsur melodi tersebut menghadirkan karakter vokal khas Aceh. Hal tersebut menciptakan sebuah kesan dalam membangun suasana baik latar waktu maupun tempat terkait hubungan realitas konflik di Aceh dengan lagu Aneuk Yatim.

Melodi menjadi salah satu ide dan gagasan yang terdapat dalam pengolahan suatu musik. Melodi merupakan suatu rangkaian tiga nada atau lebih dalam musik yang terdengar berurutan secara logis serta berirama dan mengungkapkan suatu gagasan. Di samping itu, melodi atau suara juga diartikan sebagai suksesi linier nada musik yang dianggap sebagai satu kesatuan. Dalam arti paling harfiah, melodi adalah urutan nada dan jangka waktu nada, sementara, dalam arti lain, istilah tersebut memasukkan suksesi unsur musik lain seperti warna nada. Dari beberapa pengertian tersebut, dapat disimpulkan bahwa melodi merupakan suatu susunan nada musik yang berurutan dan dianggap sebagai satu kesatuan, melodi membentuk jangka waktu yang berirama dan mengungkapkan suatu gagasan dan unsur musik lain.

Berdasarkan permasalahan yang dipaparkan di atas, penelitian ini mencoba untuk menguraikan melodi pada lagu Aneuk Yatim ciptaan Rafly Kande. Proses pencarian melodi ditandai dengan bentuk dan struktur melodi menggunakan teori musik Barat. Tujuan dari pencarian melodi dalam penelitian ini yaitu untuk mengetahui susunan melodi pada yang akan menjadi rujukan bagi karya musik Pop di Indonesia pada umumnya dan musik Pop daerah khususnya.

Secara metodologi, pendekatan yang dilakukan dalam penelitian ini menggunakan pendekatan kualitatif, dengan metode analisis deskriptif. Penelitian ini juga dibantu dengan pendekatan etik dan emik untuk mempermudah kelancaran dalam proses pencarian data. Pemilihan metode dan pendekatan dilakukan dengan interaksi langsung dalam pengumpulan data terkait subjek maupun objek. Creswell (2010:261) mengatakan bahwa dalam penelitian kualitatif peneliti adalah instrumen kunci (researcher as key instrument) yang mengumpulkan sendiri data melalui dokumentasi, observasi, dan wawancara dengan partisipan.

Sebagai bahan komparasi untuk menelaah originalitas dan menghindari plagiasi dalam kajian penelitian ini, maka dilakukan kajian pustaka untuk mencari persamaan dan perbedaan dengan penelitian sebelumnya. Salah satu penelitian terkait adalah skripsi Ade Frianto yang berjudul "Makna Pesan Sosial Dalam Lirik Lagu "Aneuk Yatim" Oleh Rafly Kande (Analisis Semiotika Tentang Makna Pesan Sosial Pada Lirik Lagu “Aneuk Yatim” Oleh Rafly Kande)". Penelitian ini terfokus pada kajian sosial yang menganalisis makna pesan sosial pada lagu “Aneuk Yatim" Oleh Rafly Kande dengan pendekatan semiotika Ferdinand de Saussure yang membandingkan antara teks sastra dengan kehidupan masyarakat Aceh di saat lagu tersebut diciptakan. Persamaan skripsi ini dengan penelitian yang dilakukan adalah sama-sama meneliti objek material yang sama, yaitu lagu "Aneuk Yatim" ciptaan Rafly Kande. Akan tetapi perbedaan penelitian ini lebih terfokus pada analisis Musikologi pada melodi lagu "Aneuk Yatim" ciptaan Rafly Kande.

Secara Teroritis, penelitian ini menggunakan teori musik Barat sebagai pembedah dalam menganalisis bentuk melodi pada lagu Aneuk Yatim ciptaan Rafly Kande. Prier (1996: 2) mengemukakan bahwa ilmu analisis musik adalah 'memotong' dan memperhatikan detil sambil melupakan keseluruhan dari sebuah karya musik. Keseluruhan berarti: memandang awal dan akhir dari sebuah lagu serta beberapa perhentian 
sementara di tengahnya; gelombang-gelombang naik turun dan tempat puncaknya; dengan kata lain: dari segi struktur.

\section{Pembahasan}

Bentuk dan struktur melodi pada lagu Aneuk Yatim ciptaan Rafly Kande secara garis besar terdiri dari dua bagian dengan tempo $60 \mathrm{bpm}$, yang masing-masing bagian dibagi dalam dua kalimat/periode. Pada kalimat tersebut disusun berdasarkan bermacam-macam bentuk motif (motif 1 , motif 2 , motif 3 , dan motif 4), yang masingmasing motif memiliki melodi dan scale yang diulang pada periode/kalimat selanjutnya dengan sedikit perubahan melodi pada akhir figures (frase penutup). Penggunaan tangganada pada lagu ini adalah Tangganada Minor Asli dan Minor Harmonis. Susunan bentuk dan struktur melodi musik lagu Aneuk Yatim, dapat dilihat pada notasi dan tabel berikut.

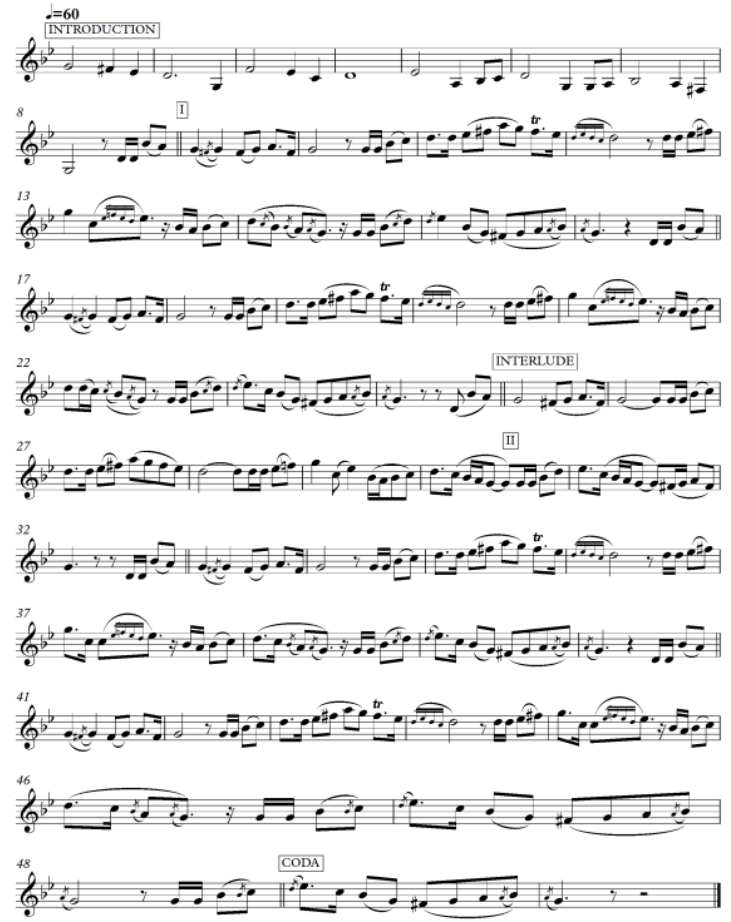

Notasi 1. Melodi Lagu Aneuk Yatim

Tabel 1. Susunan Bentuk dan Struktur Melodi Lagu AneukYatim

\begin{tabular}{|c|c|c|c|c|}
\hline Bagian & $\begin{array}{l}\text { Periode/ } \\
\text { Kalimat }\end{array}$ & Birama & Motif & Scale \\
\hline \multirow{4}{*}{$\begin{array}{c}\text { Intro- } \\
\text { duction }\end{array}$} & \multirow{2}{*}{$\mathbf{A}$} & \multirow{2}{*}{$1-4$} & $\begin{array}{l}\text { Motif a } \\
(1-2)\end{array}$ & $\begin{array}{l}\text { Minor } \\
\text { Harmonis }\end{array}$ \\
\hline & & & $\begin{array}{l}\text { Motif b } \\
(2-4)\end{array}$ & Minor Asli \\
\hline & \multirow{2}{*}{ B } & \multirow{2}{*}{$5-8$} & $\begin{array}{l}\text { Motif a } \\
(5-6)\end{array}$ & Minor Asli \\
\hline & & & $\begin{array}{l}\text { Motif b } \\
(7-8)\end{array}$ & $\begin{array}{l}\text { Minor } \\
\text { Harmonis }\end{array}$ \\
\hline \multirow{3}{*}{ I } & \multirow{3}{*}{$\mathbf{A}$} & \multirow{3}{*}{$8-16$} & $\begin{array}{l}\text { Motif a } \\
(8-10)\end{array}$ & $\begin{array}{l}\text { Minor } \\
\text { Harmonis }\end{array}$ \\
\hline & & & $\begin{array}{l}\text { Motif b } \\
(10-12)\end{array}$ & $\begin{array}{l}\text { Minor } \\
\text { Harmonis }\end{array}$ \\
\hline & & & $\begin{array}{l}\text { Motif c } \\
(12-14)\end{array}$ & $\begin{array}{l}\text { Minor Asli, } \\
\text { Minor }\end{array}$ \\
\hline
\end{tabular}

\begin{tabular}{|c|c|c|c|c|}
\hline & & & & Harmonis \\
\hline & & & $\begin{array}{l}\text { Motif d } \\
(14-16)\end{array}$ & $\begin{array}{l}\text { Minor } \\
\text { Harmonis }\end{array}$ \\
\hline & \multirow{4}{*}{$\mathbf{A}^{\prime}$} & \multirow{4}{*}{$16-24$} & $\begin{array}{l}\text { Motif a } \\
(16-18)\end{array}$ & $\begin{array}{l}\text { Minor } \\
\text { Harmonis }\end{array}$ \\
\hline & & & $\begin{array}{l}\text { Motif b } \\
(18-20)\end{array}$ & $\begin{array}{l}\text { Minor } \\
\text { Harmonis }\end{array}$ \\
\hline & & & $\begin{array}{l}\text { Motif c } \\
(20-22)\end{array}$ & $\begin{array}{l}\text { Minor Asli, } \\
\text { Minor } \\
\text { Harmonis }\end{array}$ \\
\hline & & & $\begin{array}{l}\text { Motif d } \\
(22-24)\end{array}$ & $\begin{array}{l}\text { Minor } \\
\text { Harmonis }\end{array}$ \\
\hline \multirow{4}{*}{$\begin{array}{l}\text { Interlude/ } \\
\text { Transisi }\end{array}$} & \multirow{4}{*}{-} & \multirow{4}{*}{$24-23$} & $\begin{array}{l}\text { Motif a } \\
(24-26)\end{array}$ & $\begin{array}{l}\text { Minor } \\
\text { Harmonis }\end{array}$ \\
\hline & & & $\begin{array}{l}\text { Motif b } \\
(26-28)\end{array}$ & $\begin{array}{l}\text { Minor } \\
\text { Harmonis }\end{array}$ \\
\hline & & & $\begin{array}{l}\text { Motif c } \\
(28-30)\end{array}$ & Minor Asli \\
\hline & & & $\begin{array}{l}\text { Motif d } \\
(30-32)\end{array}$ & $\begin{array}{l}\text { Minor } \\
\text { Harmonis }\end{array}$ \\
\hline \multirow{8}{*}{ II } & \multirow{4}{*}{$\mathbf{A}$} & \multirow{4}{*}{$32-40$} & $\begin{array}{l}\text { Motif a } \\
(32-34)\end{array}$ & $\begin{array}{l}\text { Minor } \\
\text { Harmonis }\end{array}$ \\
\hline & & & $\begin{array}{l}\text { Motif b } \\
(34-36)\end{array}$ & $\begin{array}{l}\text { Minor } \\
\text { Harmonis }\end{array}$ \\
\hline & & & $\begin{array}{l}\text { Motif c } \\
(36-38)\end{array}$ & $\begin{array}{l}\text { Minor Asli, } \\
\text { Minor } \\
\text { Harmonis }\end{array}$ \\
\hline & & & $\begin{array}{l}\text { Motif d } \\
(38-40)\end{array}$ & $\begin{array}{l}\text { Minor } \\
\text { Harmonis }\end{array}$ \\
\hline & \multirow{4}{*}{$\mathbf{A}^{\prime}$} & \multirow{4}{*}{$16-24$} & $\begin{array}{l}\text { Motif a } \\
(40-42)\end{array}$ & $\begin{array}{l}\text { Minor } \\
\text { Harmonis }\end{array}$ \\
\hline & & & $\begin{array}{l}\text { Motif b } \\
(42-44)\end{array}$ & $\begin{array}{l}\text { Minor } \\
\text { Harmonis }\end{array}$ \\
\hline & & & $\begin{array}{l}\text { Motif c } \\
(44-46)\end{array}$ & $\begin{array}{l}\text { Minor Asli, } \\
\text { Minor } \\
\text { Harmonis }\end{array}$ \\
\hline & & & $\begin{array}{l}\text { Motif d } \\
(46-48)\end{array}$ & $\begin{array}{l}\text { Minor } \\
\text { Harmonis }\end{array}$ \\
\hline Coda & - & $48-50$ & $\begin{array}{l}\text { Motif d } \\
(48-50)\end{array}$ & $\begin{array}{l}\text { Minor } \\
\text { Harmonis }\end{array}$ \\
\hline
\end{tabular}

Adapun bentuk bagian dan struktur pada melodi lagu Aneuk Yatim ciptaan Rafly Kande, dapat dijelaskan sebagai berikut.

a. Introduction (birama 1-8)

Bagian ini diawali dengan Introduction. Dihadirkan sebagai pembuka awal garapan komposisi/lagu di dalam musik, dengan tujuan untuk menggiring para pendengar pada suasana pada isian lagu. Introduction lagu ini terdiri dari delapan birama yang dimainkan oleh instrumen Keyboard, dan terbagi dalam dua periode/kalimat (A dan B), yang masing-masing merupakan kalimat antecedens dan consequens.

Pada periode/kalimat A (birama 1-4), terdiri dari dua motif (motif a dan motif b). Pada motif a scale yang dipakai adalah Tangganada Minor Harmonis. Selanjutnya pada motif $b$, scale yang dipakai adalah Tangganada Minor Asli.

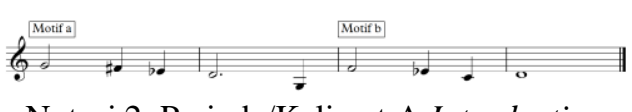

Notasi 2. Periode/Kalimat A Introduction

Pada periode/kalimat B (birama 5-8), terdiri dari dua motif (motif a dan motif b). Pada motif a, scale yang dipakai adalah Tangganada Minor Asli. 
Selanjutnya pada motif b, scale yang dipakai adalah Tangganada Minor Harmonis.

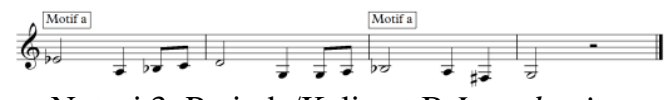

Notasi 3. Periode/Kalimat B Introduction

b. Bagian I (birama 8-24)

Bagian I memiliki 16 birama, dan terdiri dari dua periode/kalimat (A, A'). Masing-masing periode terdiri dari delapan birama, serta empat buah motif (motif a, motif $b$, motif $c$, dan motif $d$ ) yang memiliki scale yang berbeda, antara lain scale Minor Asli dan Minor Harmonis. Melodi secara keseluruhan di bagian I dimainkan oleh vokal sebagai melodi utama.

Pada periode/kalimat A (birama 8-16), terdiri dari empat motif (motif a, motif $b$, motif $c$, dan motif d). Pada motif a dan b, scale yang dipakai adalah Tangganada Minor Harmonis. Selanjutnya pada motif c, scale yang dipakai adalah Tangganada Minor Asli dan Tangganada Minor Harmonis; serta pada motif d memakai scale Tangganada Minor Harmonis. Secara keseluruhan, periode A merupakan bagian kalimat yang diulang pada periode selanjutnya, dengan perbedaan figures pada akhir frase.

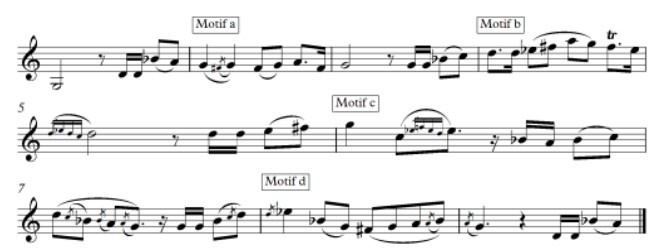

Notasi 4. Periode/Kalimat A Bagian I

Pada periode/kalimat B (birama 16-24), terdiri dari empat motif (motif a, motif $b$, motif $c$, dan motif d). Pada motif a dan b tetap sama seperti periode sebelumnya, scale yang dipakai adalah Tangganada Minor Harmonis. Selanjutnya pada motif c, scale yang dipakai adalah Tangganada Minor Asli dan Tangganada Minor Harmonis; serta pada motif d memakai scale Tangganada Minor Harmonis. Perbedaan pengulangan motif pada periode $\mathrm{B}$, terletak pada akhir figures di motif $\mathrm{c}$, notasi yang semula memakai nilai $1 / 8$ berubah menjadi notasi dengan nilai $1 / 16$ di ketukan lemah (teknik pengembangan diminished).

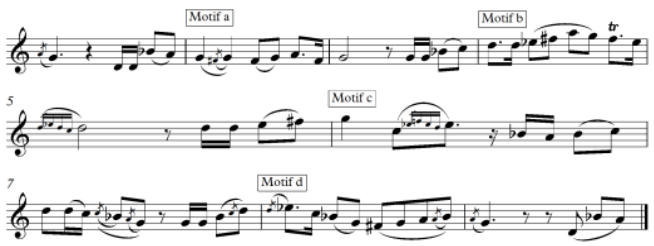

Notasi 5. Periode/Kalimat B Bagian I c. Interlude (birama 24-32)

Bagian ini merupakan periode/kalimat sebagai transisi, dan berfungsi sebagai penghubung periode/kalimat antara bagian I dan bagian II. Interlude terdiri dari sembilan birama, yang terbagi atas empat motif (motif a, motif b, motif $c$, dan motif d). Masing-masing motif merupakan pengulangan dengan teknik pengembangan motif sekuen, dimana pengulangan motif diubah pada penggunaan dan pemakaian instrumen yang dipakai, yaitu Keyboard.

Pada motif a dan b tetap sama seperti periode sebelumnya, scale yang dipakai adalah Tangganada Minor Harmonis. Selanjutnya pada motif c mengalami perubahan, scale yang dipakai adalah Tangganada Minor Asli saja; serta pada motif d memakai scale Tangganada Minor Harmonis. Bagian ini dimainkan oleh instrumen Keyboard. Selanjutnya, perbedaan pengulangan kalimat terletak pada penggunaan motif yang sedikit diubah sederhana tanpa menghilangkan melodi utama. Penyederhanaan dilakukan agar sesuai dengan kebutuhan dan kesesuaian instrumen yang dipakai.

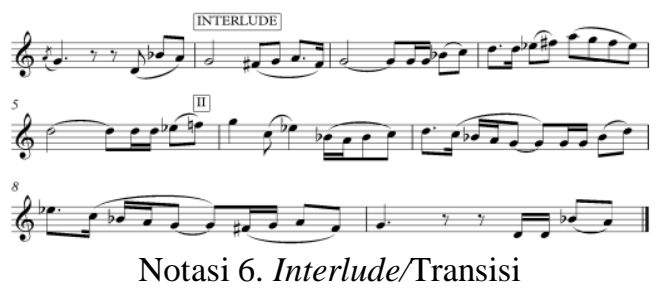

d. Bagian II (birama 32-48)

Bagian II terdiri dari 16 birama, dan dua periode/kalimat (A, A'). Masing-masing periode terdiri dari delapan birama, serta empat buah motif (motif a, motif b, motif c, dan motif d) yang memiliki scale yang berbeda, antara lain scale Minor Asli dan Minor Harmonis. Melodi secara keseluruhan di bagian I dimainkan oleh vokal sebagai melodi utama. Periode/kalimat A dan A' merupakan pengulangan utuh dengan penambahan pola ritme yang berbeda pada akhir figures di beberapa motif melodi.

Pada periode/kalimat A (birama 32-40), terdiri dari empat motif (motif a, motif $b$, motif $c$, dan motif d). Pada motif a dan b, scale yang dipakai adalah Tangganada Minor Harmonis. Selanjutnya pada motif c, scale yang dipakai adalah Tangganada Minor Asli dan Tangganada Minor Harmonis; serta pada motif d memakai scale Tangganada Minor Harmonis. Secara keseluruhan, periode A merupakan bagian kalimat yang diulang pada periode selanjutnya, dengan perbedaan figures pada akhir frase. Pengulangan dan penambahan 
pola ritme, terlihat pada motif c, figures di awal motif $\mathrm{c}$ mengalami perubahan yang semula memakai nilai nada $1 / 4$, berubah menjadi penambahan nilai nada $1 / 16$ di ketukan lemah (teknik pengembangan diminished). Perubahan juga terletak pada akhir figures pada motif c, notasi yang semula memakai nilai nada $1 / 8$, berubah menjadi notasi 1/8+1/16 (teknik pengembangan augmented).

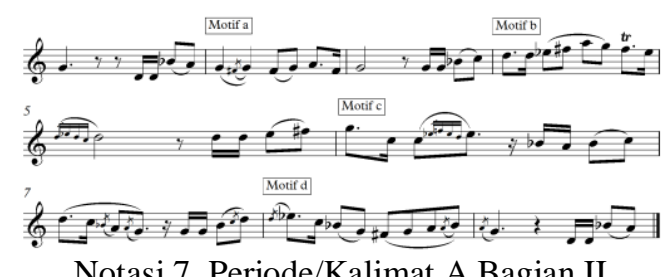

Notasi 7. Periode/Kalimat A Bagian II

Pada periode/kalimat B (birama 40-48), terdiri dari empat motif (motif a, motif $b$, motif $c$, dan motif d). Pada motif a dan b, scale yang dipakai adalah Tangganada Minor Harmonis. Selanjutnya pada motif c, scale yang dipakai adalah Tangganada Minor Asli dan Tangganada Minor Harmonis; serta pada motif d memakai scale Tangganada Minor Harmonis. Secara keseluruhan, periode B merupakan bagian kalimat yang diulang pada periode sebelumnya.

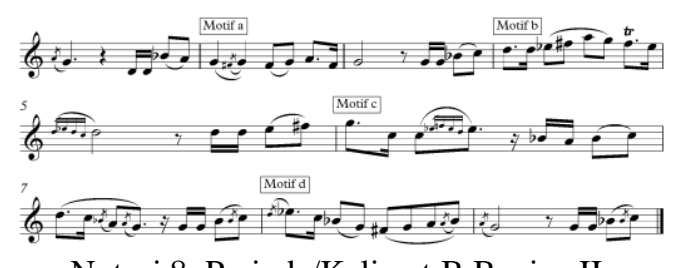

Notasi 8. Periode/Kalimat B Bagian II

e. Coda (birama 48-50)

Bagian coda merupakan bagian terakhir pada lagu, dan berfungsi sebagai bagian penutup dari semua bagian lagu. Melodi pada bagian ini tetap dimainkan oleh vokal. Coda terdiri dari empat birama, dengan memiliki satu motif yang diulang, yaitu motif $d$ pada bagian sebelumnya. Motif $d$ dimainkan satu kali, dengan pengulangan yang sama. Pengulangan motif $d$ dihadirkan dapatmenimbuklkan kesan kalimat penutup menjadi lebih tegas dan jelas.

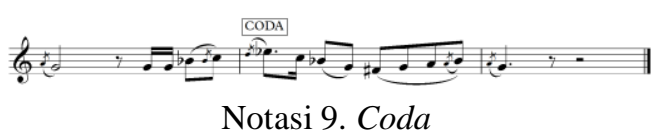

\section{Kesimpulan}

Berdasarkan penelitian terhadap melodi pada lagu Aneuk Yatim ciptaan Rafly Kande, didukung dengan pengamatan teori musik Barat, maka dapat disimpulkan beberapa hal yaitu perihal bentuk dan struktur melodi lagu Aneuk Yatim ciptaan Rafly Kande terdiri dari dua bagian (bagian I, dan bagian II),. Motif melodi pada masing-masing periode/kalimat di setiap bagian, merupakan frase utama yang diulang pada kalimat selanjutnya dengan menggunakan pengembangan pola melodi di antaranya teknik sekuen, diminished, dan augmented. Kerangka susunan melodi yang terdiri dari figures, motif, dan periode/kalimat akan membentuk kesatuan dalam melodi utuh pada lagu Aneuk Yatim ciptaan Rafly Kande.

Dalam penelitian ini baik dalam perspektif objek formal maupun objek material diharapkan agar menjadi acuan dan referensi bagi penelitian selanjutnya, terkait dengan analisis bentuk dan struktur melodi, pengembangan pola melodi dan kesatuan musik dalam melodi secara utuh yang dibahas dalam keilmuan musik Barat.

\section{Daftar Pustaka}

Aisyah Ti, dkk. 2008. Darl Islam di Aceh: Analisis Sosial Politik Pemberontakan Regional di Indonesia, 1953-1964. Lhokseumawe: Unimal Press.

Arikunto, Suharsimi. 1978. Prosedur Penelitian Suatu Pendekatan. Jakarta: Rineka Cipta.

Cresswell, John W. 2010. Research Design Pendekatan Kualitatif, Kuantitatif, dan Mixed. Yogyakarta: Pustaka Belajar.

Denada, Berlian. 2014. "Bentuk Lagu Renungan Pulau Batam karya M.Hasan di Kota Pekanbaru Provinsi Riau", dalam Skripsi. Pekanbaru: Universitas Islam Riau.

Djohan. 2009. Psikologi Musik. Yogyakarta: Penerbit Best Publisher.

Fontaine, Paul. 1967. Basic Formal Structures in Music. New York: Appleton-Century-Crofts.

Frianto, Ade. 2012. "Makna Pesan Sosial dalam Lirik Lagu 'Aneuk Yatim' oleh Rafly Kande (Analisis Semiotika Tentang Makna Pesan Sosial Pada Lirik Lagu 'Aneuk Yatim' oleh Rafly Kande" dalam Skripsi. Yogyakarta: Universitas Pembangunan Nasional "Veteran".

Hanefi. 2012. Musikologi Nusantara III. Sekolah Tinggi Seni Indonesia Padangpanjang: Padangpanjang.

Kodijat, Latifah, dkk. 1996. Tangganada dan Trinada. Jakarta: Penerbit Djambaran

Merriam, Alan P., 1987. The Study of Etnomusicology, dalam Antropology of Music. Blomington: Northwestern University Press.

Moleong, j, Lexy. 2006. Metodologi Penelitian Kualitatif. Bandung: PT. Remaja Rosdakarya.

Nazir, Muhammad. 1988. Metode Penelitian. Jakarta: Ghalia Indonesia.

Permana, Catur, Surya. 2017. "Kajian Musikologis Musik Punklung berjudul 'Bangkit Kawan'", dalam Jurnal Pendidikan dan Kajian Seni, Vol. 2 No. 1. Banten: Universitas Sultan Ageng Tirtayasa. 
Prier. SJ, Karl, Edmund. 1996. Ilmu Bentuk Musik. Yogyakarta: Pusat Musik Liturgi.

Ratna, Nyoman, Kutha. 2010. Metodologi Penelitian: kajian Budaya dan Ilmu Sosial Humaniora Pada Umumnya. Yogyakarta: Pustaka Pelajar.

Stein, Leon. 1979. Structure and Style, The Study and Analysis of Musical Forms. New Jersey: SummyBirchard Music.

Takari, Muhammad. 2015. Mengkaji Secara Saintifik Budaya Musik Aceh dari Sisi Struktural dan Fungsional. Aceh: ISBI Aceh.

Wallach, Jeremy. 2017. Musik Indonesia 1997-2001 Kebisingan dan Keberagaman Aliran Lagu (Suntingan: Rahmat Edi Susanto). Depok: Komunitas Bambu. 